presented for $2 \mathrm{sec}$ : after this, the fixation point reappeared.

The S's task was simply to say what word had been presented. The 10 Ss were all undergraduates at the University of Reading. None were familiar with the aims of the experiment.

\section{RESULTS AND DISCUSSION}

The number of correct responses, incorrect responses, and omissions are shown in Table 1 for each $\mathrm{S}$ and each display mode. Every $\mathrm{S}$ gave more correct responses in the uppercase mode than in the alternating mode; nine Ss gave more correct responses in the lower-case than in the alternating mode, with a tie occurring for the 10th $\mathrm{S}$.

This experiment, then, has shown that the alternating-case condition does, in fact, lead to impaired word identification, even when character size is the same for upper- and lowercase characters. Consequently, it seems reasonable to conclude that the failure of Smith (1969) and Smith, Lott, \& Cronnell (1969) to find such an effect was due, as was suggested above, to the insensitivity of the experimental paradigms they used. Theories of word identification which depend upon multiletter visual features are supported by our data, since such theories would predict deleterious effect of case alternation.

When asked after the experiment what kinds of letters had been presented, six of our Ss claimed that all the words had been in lower case, two claimed that all the words had been in upper case. and two claimed that. although most of the words had been in lower case. some were in upper case. No S reported awareness of the alternating case condition, even after some questioning about this. This finding in itself would seem to merit further study.

\section{REFERENCES}

Kucera, H., \& Francis, W. N. Computational analysis of present-day American English. Providence: Brown University Press, 1967

Morton, J. The effects of content upon speed of reading, eye movements and eye-voic. span Quarterly Journal of Experimental Psychology, 1964, 16, 340-355.

Reicher, G. M. Perceptual recognition as a function of meaning fulness of stimulus material. Journal of Experimental Psychology, 1969, 81, 275-280.

Rumelhart, D. E., \& Siple, P. The process of recognizing tachistoscopically presented words. Center for Human Information Processing Technical Report No. 27, University of California, San Diego, 1972.

Smith, F. Familiarity of configuration vs discriminability of features in the visual identification of words. Psychonomic Science, $1969,14,261-262$.

Smith, F., Lott, D., \& Cronnell, B. The effect of type size and case alternation on word identification. A merican Journal of Psychology, 1969, 82, 248-253.

Thompson, M. C., \& Massaro, D. W. Visual information and redundancy in reading. Journal of Experimental Psychology, $1973,98,49-54$.

Wheeler, D. D. Processes in word recognition. Cognitive Psychology, 1970, 1, 59-85.

(Received for publication October 26, 1973.)

\title{
Noncontingent reward magnitude effects on reaction time: A replication and extension*
}

\section{L. SCHURMAN and J. P. BELCHER \\ Emory University, Atlanta. Ga. 30322}

Stillings, Allen, \& Estes (1968) have demonstrated a facilitating effect of reward magnitude upon reaction time even if the reward was not contingent upon the reaction time. Their study showed anomalous results for the control group, however. They suggested that these anomalous results were due to their experimental group having a cognitive task to perform while the control group did not. Our study added a control group which did have a cognitive task (remembering a number) to perform. We replicated Stillings et al's noncontingent

*Address reprint requests to D. L. Schurman, 880 Myrtle St. N.E. No. 2, Atlanta, Ga. 30309. This research was supported in part by Emory University Grant No. 4272 to the senior author. The authors would like to express their gratitude to W. K. Estes of Rockefeller University for his advice and constructive criticisms. The conclusions and opinions expressed in this paper are the sole responsibility of the authors, however, since we did not always follow his advice. reward magnitude effect, but did not replicate the anomalous control group results. In addition, we found that the magnitude of a number to be remembered retards reaction time. Several explanations for this latter result are examined and discarded.

Stillings, Allen, \& Estes (1968) demonstrated that magnitude of reward, even though the reward was strictly noncontingent upon performance, had a measurable effect upon simple reaction time (RT) latencies. In their experiment, they measured a simple RT to a go signal (green lights). All Ss were paid cash according to the number of points amassed over the entire session, with different point values assigned to each RT trial. The optimum strategy was to respond as rapidly as possible on every trial so as to maximize the total number of points, regardless of the value of any one trial. One group of Ss was informed before each trial as to the point value of that trial. A second group was 


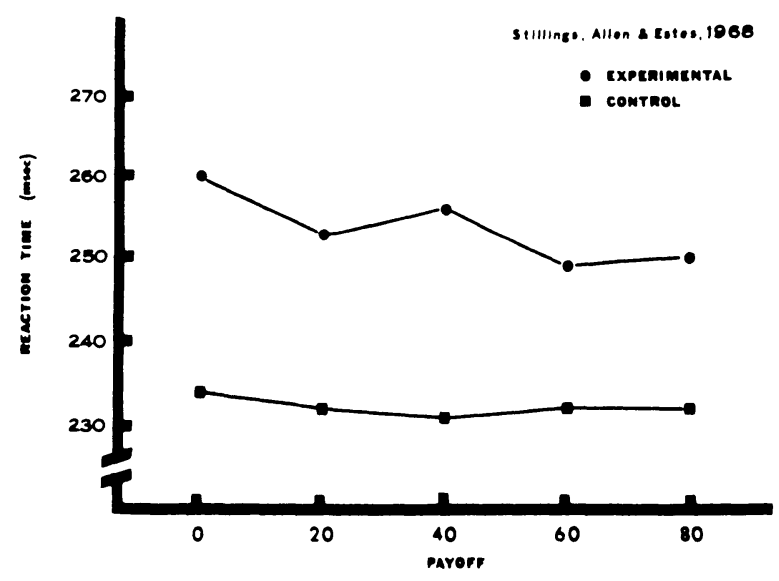

Fig. 1. Data taken from Table 1. Stillings. Allen, \& Estes, 1968. for Trials 28-54. Thanks are expressed to these authors for permission to use these data here.

not informed about trial-by'trial point values. The group which was informed of the value of each trial responded more rapidly on high-value trials than on low-value trials. The group which was uninformed about the value of each trial responded at about the same speed on all trials.

A problem appears in these data. however. As is shown in Fig. 1. the uninformed group responded faster than the informed group at all levels. One would have expected the uninformed group to have responded at either the mean level or the fastest level of the responses for the informed group. Stillings et al (1968) suggest that this odd difference may be due to the uninformed Ss having only a blank patch of light as a warning signal during the 1-2.5-sec foreperiod. whereas the informed Ss were shown the point value of the trial during the foreperiod. The argument is that the additional processing of point values may have slowed overall RT for the informed group.

The overall RT differences between the two groups does not detract from the main result of noncontingent reward magnitude effects. Nonetheless, this difference is bothersome. The Stillings et al (1968) suggestion above did not seem compelling to us, but the suggestion is testable. Therefore, the following experiment was designed as a replication of noncontingent reward magnitude effects and to test for effects of a nonrelevant processing task on simple RT.

\section{METHOD}

\section{Subjects}

Sixty Emory University undergraduates from the introductory $\mathrm{S}$ pool served as Ss. All Ss received a standard amount of course credit plus a differential pay incentive based on the number of points amassed during the $40-\mathrm{min}$ session. The average pay was about $\$ 1.75$. All Ss were naive with regard to RT and incentive reward experiments.

\section{Apparatus}

Stimulus displays were presented with a Iconix four-field tachistoscope. One field of the tachistoscope was used to present either a blank flash of light as a warning signal (for one group) or numbers (for the other two groups). The warning and number fields appeared for the entire 1.00-, 1.50-, 1.75-, 2.00-, or $2.50-\mathrm{sec}$ foreperiod and were $9 \mathrm{~mL}$ in intensity. The "go" signal was the onset of tour green lights in another field of the tachistoscope. The lighits appeared symmetrically arranged about the number location. The response was the right-hand depression of a telegraph key. A Hunter Klockounter (Model 120-A) was used to measure RT. The numbers (when displayed) subtended a visual angle of $0.75 \mathrm{deg}$ at the viewing distance of $1.5 \mathrm{~m}$.

\section{Procedure}

All Ss were randomly divided into three groups, 20 Ss per group. All Ss were instructed to depress the response key as quickly as possible when the green lights appeared. They were each given five practice trials, with $\mathrm{E}$ giving a verbal warning signal. All Ss were then informed that each trial would be worth $0,20,40,60$, or 80 points, and that they would be paid for the total number of points amassed during the 40 -min session. By responding as quickly as possible on every trial, Ss would maximize their pay-and they were so informed.

The blank control group received a blank flash of light during the foreperiod and no information about the point value of the trial. The experimental group Ss were shown the point value of each trial during the foreperiod. The third group, the cognitive control group, saw the numbers $0,15,45,75$, or 90 during the foreperiod of each trial. These cognitive control group Ss were further informed that these numbers bore absolutely no relationship to the point value of each trial. These Ss were instructed to recall and repeat this number after making the RT response.

The five point values and the five to-be-recalled (TBR) numbers were systematically varied across Ss by means of orthogonal, randomized Greco-Latin squares. The five foreperiod delays were systematically distributed and counterbalanced across trials such that each delay period occurred with each point value of trial equally often over 100 trials. Intertrial intervals varied from 25 to $45 \mathrm{sec}$, depending on the number of manipulations required of $\mathrm{E}$ for the trial.

All trials in which RT latencies exceeded $500 \mathrm{msec}$ were rerun during the session (less than $2 \%$ for each group). Any $S$ who gave an overall mean RT greater than $300 \mathrm{msec}$ was randomly replaced. Two Ss from each group were dropped by this criterion.

\section{RESULTS AND DISCUSSION}

The incentive effect of magnitude of the noncontingent reward found by Stillings et al (1968)

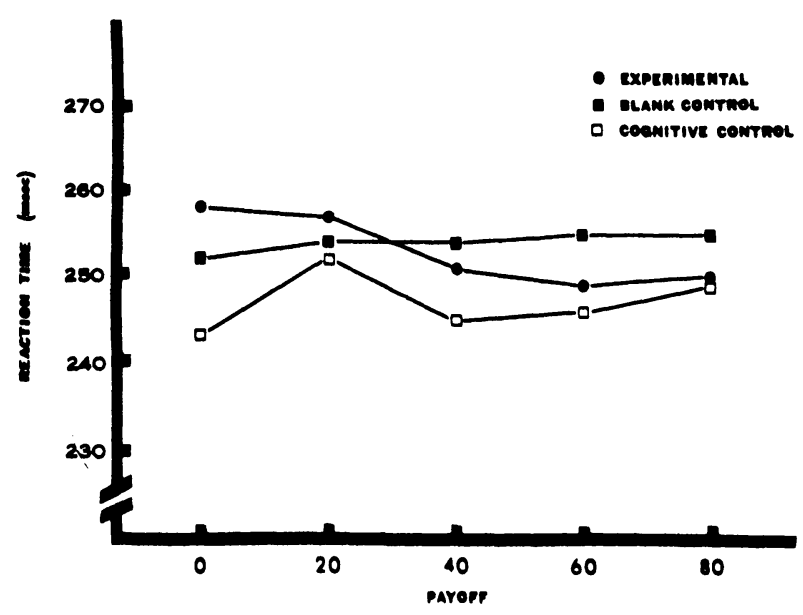

Fig. 2. Simple RT to the onset of lights averaged across 18 trials per $S$ and 20 Ss per condition. 


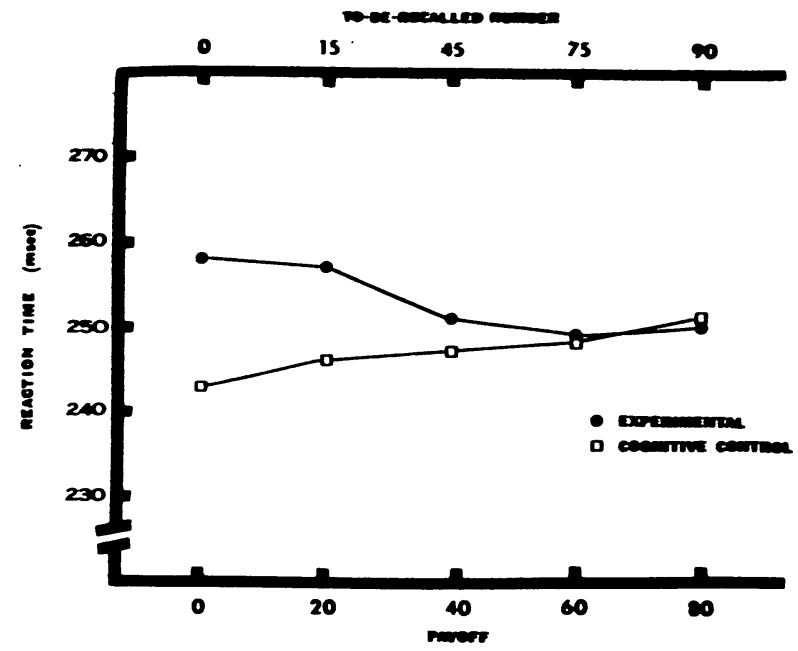

Fig. 3. Comparison of RT as a function of payoff value for the experimental group and as a function of TBR number for the cognitive control group.

was replicated, as is shown in Fig. 2. The difference between 0 - and 80-point-value RTs for the experimental group is reliable by a $t$ test for paired measures $(t=2.44$, $\mathrm{df}=19, \mathrm{p}<.05)$. Because our equipment was manually controlled. we were able to obtain only 18 trials per payoff condition rather than the 54 obtained by Stillings et al. Thus, the effect shown by this replication is more robust than that from the original study. On the other hand. the unusual differences between blank control and experimental groups, which originally excited our curiosity, did not replicate. The difference between the blank control and cognitive control groups, which is apparent in Fig. 2, disappears when a single S, who did not produce any mean RT less than $300 \mathrm{msec}$, is subtracted from the blank control group means. (This $\mathrm{S}$ slipped past our criterion through error.) Without this $S$, the curves for the two groups are virtually identical.

An additional analysis of the cognitive control group data, analyzing mean RT by TBR number, was performed. Since point value and TBR were orthoganal, the cognitive control group would have shown about these same mean RT per payoff values if these Ss has simply believed the TBR numbers to be the point value on each trial. The results of calculating mean RT for each TBR number is shown in Fig. 3. This result was quite unexpected. Not only is there no positive effect for magnitude of the TBR numbers, there is a strong reverse effect! A correlated t test for TBR numbers 0 and 90 yielded $t=-3.47, \mathrm{df}=19, \mathrm{p}<.05$. The effect of magnitude of reward. then, is overcoming a strong reverse effect of magnitude of the displayed number. Thus, this magnitude of noncontingent reward effect must be much stronger than Stillings et al realized.

On the other hand, the results displayed in Fig. 3 raise an even more intriguing question than did the magnitude of reward effects. Why should the magnitude of a displayed number have any adverse effect upon RT? We considered and rejected the following post how explanations: (1) Any differences in discriminability for our TBR numbers should have been minimal for these exposure durations of $1.0-2.5 \mathrm{sec}$. Indeed. a quick inspection indicates that 90 is easier to discriminate than 45 or 15 at short durations. (2) Rehearsal time for these numbers could be a function of magnitude. and the shorter foreperiod durations might be so brief that rehearsal was still in progress when the "go" signal occurred. However. examination of RT for the control groups at each foreperiod duration showed no differences between them for the 1.0-sec and all other durations. Measurement witt: an oscilloscope of the time to speak these numbers indicated that " $45^{\text {" takes about }}$ twice as long to say as "90" does. (3) Yet another possibility was suggested by the experiment of Lovelace \& Snodgrass (1971), who found RT to the alphabetical order of letter pairs to be systematically related to the ordinal position of the letters in the alphabet. The mean RT to letters near the end of the alphabet was slower than that to letters near the beginning. Although this task is not comparable to ours (our TBR numbers were not the "go" signal), there might be some commonality between effects of ordinal position. We tested four Ss. in a quick look at this possibility, using the letters A. F. K. $\mathrm{P}$, and $\mathrm{U}$. The letters were displayed during the foreperiod and were to be recalled. The same four green lights were the "go" signal. No trends were found for these letters.

Ordinality is, of course, a much stronger feature of numbers than of letters, since the ordinal position of numbers also involves magnitude. Nevertheless, it is not clear why magnitude of a TBR number should have any effect on RT to green lights.

\section{CONCLUSIONS}

The main result of Stillings et al (1968) was replicated. The magnitude of a noncontingent reward facilitates simple RT to the onset of a "go" signal. The data from our cognitive control group, which had an irrelevant processing task (numbers to be recalled). showed a magnitude effect stronger in the reverse direction than the facilitating effect found by Stillings et al (1968).

There is no obvious, to us, reason why the magnitude of a TBR number should affect simple RT. Bernstein. Pederson. \& Schurman (1972) did find a general retardation of RT when an irrelevant visual stimulus was presented prior to the onset of a visual target. They explained this finding as a distraction effect. Unfortunately, this finding is of limited use in explaining our results with TBR numbers, since the differential distraction for magnitude of the TBR number would still require explanation.

\section{REFERENCES}

Bernstein, I. H., Pederson, N. N., \& Schurman, D. L. Intersensory versus intrasensory contingent information processing. Journal of Experimental Psychology, 1972, 94, 156-161.

Lovelace, E. A., \& Snodgrass, R. D. Decision times for alphabetic order of letter pairs. Journal of Experimental Psychology, $1971,88,258-264$.

Stillings, N. A., Allen, G. A., \& Estes, W. K. Reaction time as a function of noncontingent reward magnitude. Psychonomic Science, $1968,10,337-338$.

(Received for publication October 29, 1973.) 